\title{
Contamination and harm relevant UCS-expectancy bias in spider phobic individuals: influence of treatment.
}

Citation for published version (APA):

van Overveld, M., de Jong, P. J., Huijding, J., \& Peters, M. L. (2010). Contamination and harm relevant UCS-expectancy bias in spider phobic individuals: influence of treatment. Clinical Psychology \& Psychotherapy, 17, 510-518. https://doi.org/10.1002/cpp.678

Document status and date:

Published: 01/01/2010

DOI:

$10.1002 /$ cpp.678

Document Version:

Publisher's PDF, also known as Version of record

Document license:

Taverne

Please check the document version of this publication:

- A submitted manuscript is the version of the article upon submission and before peer-review. There can be important differences between the submitted version and the official published version of record.

People interested in the research are advised to contact the author for the final version of the publication, or visit the DOI to the publisher's website.

- The final author version and the galley proof are versions of the publication after peer review.

- The final published version features the final layout of the paper including the volume, issue and page numbers.

Link to publication

\footnotetext{
General rights rights.

- You may freely distribute the URL identifying the publication in the public portal. please follow below link for the End User Agreement:

www.umlib.nl/taverne-license

Take down policy

If you believe that this document breaches copyright please contact us at:

repository@maastrichtuniversity.nl

providing details and we will investigate your claim.
}

Copyright and moral rights for the publications made accessible in the public portal are retained by the authors and/or other copyright owners and it is a condition of accessing publications that users recognise and abide by the legal requirements associated with these

- Users may download and print one copy of any publication from the public portal for the purpose of private study or research.

- You may not further distribute the material or use it for any profit-making activity or commercial gain

If the publication is distributed under the terms of Article $25 \mathrm{fa}$ of the Dutch Copyright Act, indicated by the "Taverne" license above, 


\title{
Contamination and Harm Relevant UCS-Expectancy Bias in Spider Phobic Individuals: Influence of Treatment
}

\author{
Mark van Overveld, ${ }^{* 1}$ Peter J. de Jong, ${ }^{2}$ Jorg Huijding ${ }^{3}$ \\ and Madelon L. Peters ${ }^{4}$ \\ ${ }^{1}$ Marketing Management, Erasmus University Rotterdam, the Netherlands \\ ${ }^{2}$ Department of Clinical and Developmental Psychology, University of \\ Groningen, the Netherlands \\ ${ }^{3}$ Clinical Psychology, Erasmus University Rotterdam, the Netherlands \\ ${ }^{4}$ Department of Clinical Psychological Science, Maastricht University, the \\ Netherlands
}

Phobic individuals expect aversive UCS's following encounters with phobic stimuli. Previous research using a thought-experiment procedure showed that contamination rather than harm-related outcome expectancies differentiated best between high and low spider fearful undergraduates. This study investigated the alleged role of these UCS-expectancy biases in the maintenance of phobic complaints. First, this study sought to replicate these earlier findings in a community sample of high spider fearful individuals who applied for treatment $(n=60)$ and a sample of low spider fear controls $(n=$ 30). Second, the present study tested if UCS-expectancies disappear following successful treatment and whether there were any differences between harm and contamination-related UCS expectancies in this respect. If contamination- and/or harm-related UCS-expectancy biases play a critical role in the maintenance of spider fear, these biases should be substantially reduced after successful treatment. The results showed that spider fearful individuals associated spiders relatively strongly with both harm- and contamination-related outcomes. Consistent with the alleged reciprocal relationship between phobic fear and UCS expectancy bias, both types of biased expectancies were effectively reduced following treatment. Copyright $@ 2010$ John Wiley \& Sons, Ltd.

Key Practitioner Message:

- It will be studied whether disgust and fear are both important factors in spider phobia.

- It is investigated whether a contamination-related UCS-expectancy bias is specific to spiders or to disgusting objects in general.

- It is examined whether contamination-related UCS-expectancies can be effectively diminished using the treatment of choice in specific phobias, exposure in vivo.

*Correspondence to: Mark van Overveld, Erasmus University Rotterdam, Woudestein, T10-16, P.O. Box 1738, 3000 DR Rotterdam, the Netherlands.

E-mail: MOverveld@RSM.nl 
Keywords: Spider Phobia, Treatment, Exposure In Vivo, Disgust, Contamination, UCS-Expectancy Bias

\section{INTRODUCTION}

Recent models of specific phobias assume that cognitive biases play an important role in the genesis and maintenance of these phobias (Davey, 1997). One such bias is the UCS-expectancy bias, which can be defined as the tendency to over-associate phobia-relevant conditioned stimuli (CS) with the occurrence of specific stimuli (Un Conditioned Stimulus (UCS)) (e.g., Davey, 1992a; Tomarken, Mineka, \& Cook, 1989; van Overveld, de Jong, \& Peters, in press). Previous work demonstrated that spider fearful undergraduates display UCSexpectancy biases for aversive outcomes following exposure to spiders, whereas non-spider fearful individuals generally do not (Cavanagh \& Davey, 2000; van Overveld, de Jong, \& Peters, 2006). Additionally, although differential UCS-expectancies exist for various animals (Davey, Cavanagh, \& Lamb, 2003; van Overveld et al., 2006), only expectancy biases for phobia-relevant animals (i.e., spiders) were significantly more pronounced in spider fearful individuals (van Overveld et al., 2006). Thus, UCS-expectancies only appear inflated for phobia-relevant stimuli. Moreover, spider fearful individuals do not only markedly overestimate UCS-expectancies of a fearful outcome following a hypothetical exposure to a spider in comparison to non-fearful participants, they also consistently underestimate the probability of a fearful outcome following fear-irrelevant stimuli (Cavanagh \& Davey, 2000). Such cognitive biases may maintain fear of spiders by inducing behavioural avoidance towards fear-relevant stimuli (e.g., Jones \& Menzies, 2000; Whittal \& Goetsch, 1997), thereby reducing the opportunity for the extinction of fear. Moreover, avoidance of the CS (i.e., spiders) will impede the correction of UCS-expectancy biases (Davey, 1997).

There is increasing evidence that in addition to harm/fear-related UCS-expectancies, contaminationrelated expectancies are involved in spider fear. Spider fearful individuals are characterized by disgust and contamination-related associations for spiders on explicit (de Jong \& Muris, 2002; van Overveld et al., 2006) as well as implicit measures (Huijding \& de Jong, 2007). Furthermore, spider fearful individuals do not only display an UCS-expectancy bias for harm-related consequences, but also display a contamination-related UCS-expectancy bias for spiders (van Overveld et al., 2006). Underlining the relative importance of contamination-related UCSexpectancies in spider fear, previous work showed that a contamination-related UCS-expectancy bias was the single best predictor of phobic avoidance during a behavioural approach task (de Jong \& Peters, 2007).

The present study investigated the role of contamination-related UCS-expectancy bias in the maintenance of phobic complaints. As an important first step, the present study sought to replicate earlier findings in a community sample of high spider fearful individuals who applied for treatment. As a second step, the present study tested if contamination-related UCS-expectancies disappear following successful treatment. If contamination-related UCS-expectancy bias plays a critical role in the maintenance of spider fear, this bias should be substantially reduced after successful treatment. Since the effects of treatment on contamination-related UCS-expectancies have not yet been explored, this experiment is the first to examine this.

To test whether enhanced expectancy biases in high spider fearful individuals are confined to spiders, or instead, represent a more generally enhanced harm- and/or contamination-related UCS expectancy bias, two additional categories were included in the design: low-predation disgustrelevant animals (maggots) and high-predation fear-relevant animals (pitbull terriers) (see also Davey et al., 2003; van Overveld et al., 2006). Consistent with previous research on UCS expectancy bias we used a thought-experiment procedure. Accordingly, the present study relied on UCSexpectancies regarding hypothetical exposure to a spider rather than actual exposure with spiders. This requires participants to be able to accurately report how they would respond when they would be confronted with a spider, and one may argue whether individuals are indeed (always) able to do so. Clearly, then this approach has limitations as UCS-expectancies in real-life situations may not fully correspond with those in hypothetical situations (e.g., Parkinson \& Manstead, 1993). However, what is of major concern here is what type of UCSexpectancies people hold when they explicitly consider the possibility of exposure to a spider. It seems that such explicit considerations regarding the anticipated effects of exposure to a phobic object can be reasonably successfully investigated with a hypothetical thought experiment procedure. 


\section{METHOD}

\section{Participants}

High spider fearful individuals $(n=60)$ were recruited through articles in newspapers and magazines regarding our ongoing spider phobia project as well as via posters and advertisements in local and regional media indicating that our department offers free treatment against spider phobia for individuals who are willing to participate in scientific research. An explicitly non-fearful control group $(n=30)$ was recruited via posters and advertisements in local media. The non-fearful participants received a small remuneration for taking part in the study. The mean score on the Spider Phobia Questionnaire (SPQ) for the high-fearful participants $(M=20.8 ; \mathrm{SD}=4.15)$ was comparable to SPQ scores reported in other exposure treatment studies (e.g., Teachman \& Woody, 2003, $M=19.7 ; \mathrm{SD}=4.75)$. The high fearful and non-fearful groups were comparable in sex, age and educational level. Participants in both groups were predominantly female $(81.7 \%$ and $80 \%$, respectively). Further, of the high spider fearful individuals, $12.7 \%$ completed only primary education, $45.5 \%$ completed secondary education and $41.8 \%$ completed tertiary educational levels. This group had a mean age of 34.0 years $(\mathrm{SD}=11.1$; range $19-77)$. Of the low spider fearful group, 3.6\% completed primary education, $53.6 \%$ completed secondary education and $42.9 \%$ obtained tertiary educational levels. This group had a mean age of 35.2 years ( $\mathrm{SD}=13.1$; range $18-58)$.

\section{Materials}

$S P Q$

The SPQ examines an individual's fear of spiders. Participants rate their agreement with 31 items on a dichotomous scale (yes $=1 /$ no $=0$ ) (e.g., 'I dislike looking at pictures of spiders in a magazine'). Thus, a sum score ranging between 0 and 31 is obtained. Higher scores reflect higher levels of spider fear. The SPQ is internally consistent with Cronbach's alphas between 0.83 and 0.91 (Klorman, Weerts, Hastings, Melamed, \& Lang, 1974; 0.91, present study).

\section{UCS-Expectancy Questionnaire}

This questionnaire assesses participants' expectancies that an aversive consequence will occur following a hypothetical exposure to a specific animal. The UCS-expectancy questionnaire was used in previous research (van Overveld et al., 2006) and is based on the procedure originally designed by McNally and Heatherton (1993). Before completing the questionnaire, participants receive a verbal introduction in which they are asked to imagine as vividly as possible that they are about to participate in an experiment, where they will view a series of slides depicting several animal types (i.e., dogs, rabbits, maggots and spiders). Participants are told that after each slide, one of three possible consequences will occur: an electrical shock is administered, they have to drink a sip of a disgusting juice, or nothing happens. After this verbal introduction, participants rate how many of the slides depicting a certain animal type (i.e., dogs, rabbits, maggots and spiders) they believe will be followed by the three consequences on a 100$\mathrm{mm}$ visual analogue scale (VAS), ranging from 0 ('none at all') to 100 ('all'). This results in 12 UCSexpectancy judgments ( 4 animals $\times 3$ consequences). The sequence of the UCS-ratings was randomized. Next, the resulting sequence was fixed in the sense that all participants then rated the items in that particular order (see van Overveld et al., 2006 and the verbal introduction in the Appendix). As we were interested in the specific UCS-expectancies for each animal type, UCS-expectancies were calculated by subtracting the expectancy of a neutral outcome from the outcome of interest (e.g., contaminationexpectancy for spiders $=$ UCS-expectancy of a sip of juice after spiders-UCS-expectancy of the neutral consequence after spiders).

To control for the influence of undesirable testretest effects that might undermine the sensitivity of the present design for testing the influence of treatment on UCS-expectancy bias, one group of high fearful participants $(n=30)$ only completed the UCS-questionnaire after treatment ('post-treatment group'), whereas a second group of high fearful participants $(n=30)$ were tested both before and after treatment (c.f. de Jong, Merckelbach, Arntz, \& Nijman, 1992) ('treatment effects group').

\section{Behavioural Approach Task (BAT)}

The BAT is a widely used instrument to assess the degree of avoidance for specific stimuli such as spiders (Arntz, Lavy, van den Berg, \& Rijsoort, 1993; de Jong, Vorage, \& van den Hout, 2000). Here, participants approach a medium-sized common house spider (Tegenaria atrica) in eight steps, ranging from looking at a spider in a closed jar, to having a spider walk on their hands. The steps increased in difficulty and participants were informed that they could stop at any point. After each step, two VAS scores (from 0100) were completed to assess peak anxiety and peak disgust.Participants'scorewascalculated by summing the amount of actual steps taken on the BAT (range: 0-8). Thus, high BAT-scores represent low avoidance of spiders. 


\section{Treatment}

All spider fearful individuals received a 2.5hour, single-session exposure in vivo treatment (see also Öst, 1989). During this procedure, participants were intensively exposed to spiders, had to approach spiders actively, and remained in contact with them until their fear would fade away. This treatment is one of the most effective treatments available in reducing fear of spiders (Choy, Fyer, \& Lipsitz, 2007; Öst, 1989). The treatment was conducted by five female students at the university of Groningen, who successfully passed a training course on how to administer this particular type of therapy and followed a Dutch protocol (de Jong \& Keijsers, 1999) based on the work of Öst (1989).

\section{Procedure}

High fearful participants were randomly assigned to one of two groups. Participants in the treatment effects' group participated in the experimental procedure before they received treatment. To allow testing of the influence of repeated assessment this group also completed the experiment after treatment. Participants in the 'post-treatment' group first underwent a 2.5-hour exposure in vivo treatment before participating in the experiment.

On arrival at the lab, all participants completed the SPQ. Only the 'treatment effects' group and the control participants also completed the UCSexpectancy questionnaire at this point. After this, all participants conducted a BAT with a real-life medium sized common house spider. For the low fearful group, the data acquisition for the present experiment ended here. However, this research was part of a larger study, so all participants also completed several computer tasks (see Huijding \& de Jong, 2007). High spider fearful individuals $(n=60)$ then received a one-session exposure in vivo treatment. After the treatment session, both fearful groups received the UCS-questionnaire and completed a second BAT.

\section{RESULTS}

\section{Descriptive Statistics}

Table 1 depicts the mean scores of the high and low spider fearful groups on all questionnaires. A one-way analysis of variance (ANOVA) confirmed that high spider fearful individuals were characterized by significantly higher levels of spider fear compared with low spider fearful individuals, as measured by the SPQ $(F[1,87]=430.38, p<0.01$, $\left.\eta^{2}=0.83\right)$. Further, the number of BAT-steps taken on the BAT prior to treatment was significantly lower in the high spider fearful group than in the low spider fearful group $(F[1,89]=87.71, p<0.01$, $\left.\eta^{2}=0.50\right)$. In addition, the spider fearful group reported experiencing significantly higher levels of peak fear $\left(F[1,89]=195.95, p<0.01, \eta^{2}=0.69\right)$ and peak disgust $\left(F[1,89]=49.38, p<0.01, \eta^{2}=0.36\right)$ during the last step of the BAT.

Next, a series of paired sample $t$-tests were used to compare post-treatment measurements with pre-treatment measurements. To correct for family wise error, Bonferroni corrected alphas were set to 0.0125 . These revealed that, post treatment, spider fearful individuals displayed a significant decrease in self-reported spider phobic complaints (SPQ) $\left(t[59]=10.05, p<0.01, \eta^{2}=1.29\right)$, as well as an increase in the number of BAT-steps taken $\left(t[58]=-12.25, p<0.01, \eta^{2}=1.52\right)$, and a significantly decreased level of peak disgust $(t[57]=$ $\left.6.90, p<0.01, \eta^{2}=0.87\right)$ and peak fear $(t[58]=6.35$, $\left.p<0.01, \eta^{2}=1.08\right)$ during the BATs.

\section{UCS-Expectations for all Animal Types}

A 4 (Animal: rabbits, maggots, dogs, spiders) $\times$ 2 (Outcome: shock minus nothing, juice minus

Table 1. Mean scores on the SPQ, mean number of BAT steps and mean peak fear and disgust during the final BATstep for high and low spider fearful groups at pre- and post-treatment measurements

\begin{tabular}{|c|c|c|c|c|c|c|}
\hline \multirow[b]{2}{*}{ Indices } & \multicolumn{2}{|c|}{ Low fear } & \multicolumn{4}{|c|}{ High fear } \\
\hline & Pre & Range & Pre & Range & Post & Range \\
\hline SPQ & $2.40(3.59)$ & $0-17$ & $20.83(4.15)$ & $10-28$ & $14.00(6.25)$ & $3-27$ \\
\hline BAT-steps & 7.77 (0.92) & $4-8$ & $3.85(2.13)$ & $0-8$ & $6.90(1.84)$ & $1-8$ \\
\hline Peak fear & $8.33(14.52)$ & $0-50$ & $77.88(25.15)$ & $0-100$ & $45.51(33.91)$ & $0-100$ \\
\hline Peak disgust & $4.17(13.46)$ & $0-70$ & $55.17(38.50)$ & $0-100$ & $25.26(30.9)$ & $0-100$ \\
\hline Valid $n$ & \multicolumn{2}{|c|}{30} & \multicolumn{2}{|c|}{60} & \multicolumn{2}{|c|}{60} \\
\hline
\end{tabular}

Note. Standard deviations are described between parentheses.

$\mathrm{BAT}=$ behavioural approach task. SPQ = Spider Phobia Questionnaire. 
nothing) $\times 2$ (Group: low spider fearful, high spider fearful) ANOVA was used to determine if earlier findings on UCS-expectancies could be replicated. For this analysis, only the control and 'treatment effects' groups were included. As expected, the analysis showed that the various classes of animals were differentially associated with specific outcomes (animal $\times$ outcome: $F[3,54]=9.24, p<0.01$, $\left.\eta^{2}=0.34\right)$. Generally, outcome expectancies for the various slides were similar for high and low spider fearful groups (animal $\times$ outcome $\times$ group: $\left.F[3,54]=0.90, p=0.45, \eta^{2}=0.05\right)$.

To examine more specifically which animals were associated with each outcome, a series of 3 (outcome: neutral, shock, juice) $\times 2$ Group (low spider fearful, high spider fearful) ANOVAs were conducted for the Animal types that were expected to evoke similar expectancies across groups (i.e., rabbits, maggots, dogs). In line with earlier work, rabbits were most strongly associated with nothing (nothing compared with shock: $F(1,59)=171.87, p<0.001, \eta^{2}=$ 0.74 ; nothing compared with juice: $F(1,59)=177.71$, $\left.p<0.001, \eta^{2}=0.75\right)$. Maggots were associated most strongly with juice (juice compared with nothing: $F(1,57)=12.43, p<0.001, \eta^{2}=0.18$; juice compared with shock: $\left.F(1,57)=30.83, p<0.001, \eta^{2}=0.35\right)$ and dogs were associated equally strongly with shock and nothing (shock compared with nothing: $F[1,58]$ $=0.04, p=0.84, \eta^{2}<0.01$ ), whilst associations with juice were significantly lower (juice versus nothing: $F[1,58]=5.75, p=0.02, \eta^{2}=0.09$; juice compared with shock: $\left.F[1,58]=14.37, p<0.001, \eta^{2}=0.20\right)$. A visual summary is presented in Figure 1a,b.

To specifically test our hypothesis (that the fearful group will demonstrate enhanced UCS expectancy bias only for spider slides) with retaining optimal power we carried out a second analysis that was restricted to spider slides. This 2 (outcome: shock minus nothing, juice minus nothing) $\times 2$ (group: low, high spider fearful) ANOVA revealed that although both high and low fearful groups expected similar outcomes following a spider slide (outcome $\times$ group: $F[1,57]=0.87, p=0.35, \eta^{2}=0.02$ ), the high spider fearful group reported significantly stronger expectancies of both outcome types compared with the neutral outcome (group: $F[1,57]=17.23$, $p<0.001, \eta^{2}=0.23$ ) following a spider than the low spider fearful group.

\section{UCS-Expectancies for Spiders Following Treatment}

First, correcting for the influence of possible carryover effects from completing the same questionnaire twice, we compared the pre-treatment UCSexpectancies (shock minus nothing, juice minus nothing) for spiders in the 'treatment effects' group to the post-treatment UCS-expectancies for spiders of the 'post-treatment' group. ${ }^{1}$ The post-treatment UCS-expectancies for spiders of the 'treatment effects group' were thus excluded in the current analysis, as these participants completed the questionnaire twice. Thus, a 2 (outcome: shock minus nothing, juice minus nothing) $\times 2$ (treatment effect: treatment effects, post-treatment) ANOVA was used. The main effect of treatment effect was significant $\left(F[1,58]=11.82, p<0.01, \eta^{2}=0.17\right)$, indicating that UCS-expectancies for spiders differed between pre- and post-treatment measurements. The absence of a significant outcome $\times$ treatment effect interaction $\left(F[1,58]=0.15, p=0.70, \eta^{2}<0.01\right)$ indicated that UCS-expectancies for both outcome types were similarly lower in the post-treatment group. Additionally, a 2 (outcome: shock minus nothing, juice minus nothing) $\times 2$ (time: pre-treatment, post-treatment) ANOVA in the 'treatment effects' group was conducted to examine the decrease in UCS-expectancies for spiders in individuals with both a pre- and post-treatment assessment. This similarly showed that both expectancies for harm- and contamination-related outcomes were indeed reduced effectively following treatment as indicated by a significant main effect for time $\left(F[1,28]=21.93, p<0.01, \eta^{2}=0.44\right)$.

To examine the level of UCS-expectancy bias for spiders after treatment, a 2 (Outcome: shock minus nothing, juice minus nothing) $\times 2$ (spider fear: control group, both clinical groups combined) ANOVA was conducted. This revealed that treatment effectively reduced UCS-expectancies for spiders to normative levels, as indicated by the absence of a significant interaction term outcome $\times$ spider fear $\left(F[1,86]=1.49, p=0.23, \eta^{2}=0.02\right)$ and a non-significant main effect for spider fear $\left(F[1,86]=0.33, p=0.57, \eta^{2}<0.01\right)$.

\footnotetext{
${ }^{1}$ To determine whether any carry-over effects were present, a 2 (outcome: shock minus nothing, juice minus nothing) $\times$ 2 (treatment Effects: 'treatment effects' group, 'post treatment' group) $\times 3$ (animal: rabbit, dog, maggots) ANOVA was conducted. Spiders were not included as treatment was expected to influence UCS-expectancies for spiders. Thus, for the other animal types, post-treatment UCS-expectancies of the 'treatment effects' group were compared with the post-treatment UCS-expectancies of the 'post-treatment' group. The absence of a main effect of treatment effect $\left(F[1,57]=0.61, p=0.44, \eta^{2}=0.01\right)$ indicated that no carry over effects were found as there were no differences in UCSexpectancies for the other animals between the group with and the group without a pre-treatment measurement.
} 


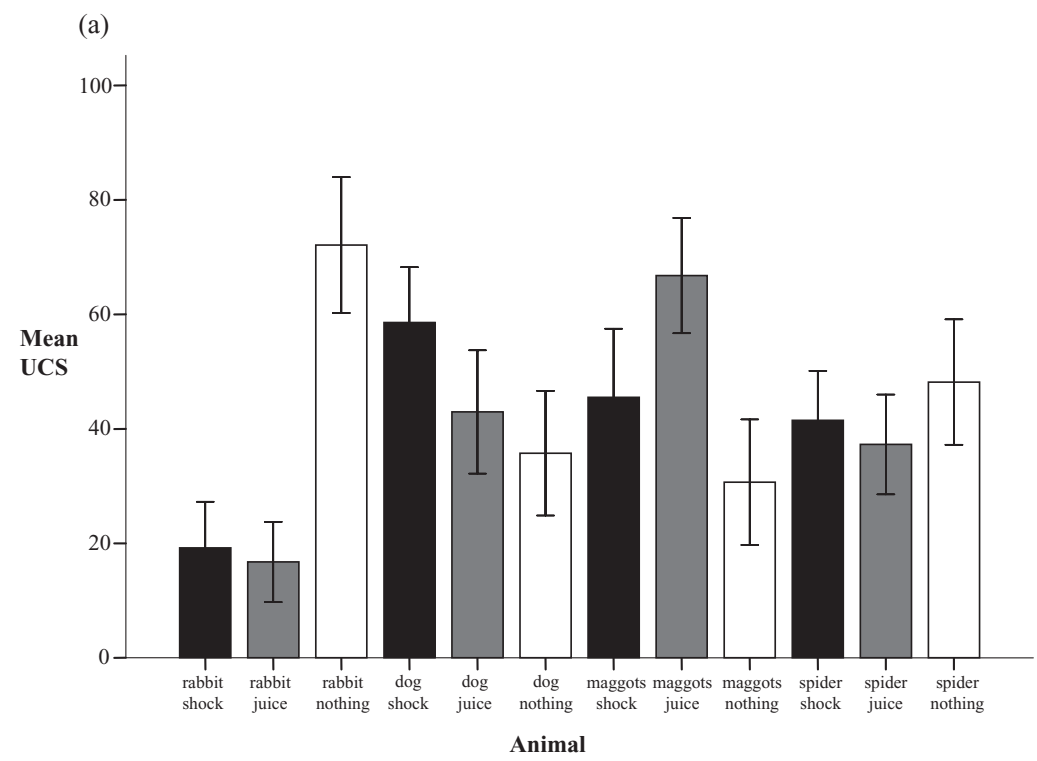

Error Bars: +/- 2 SE

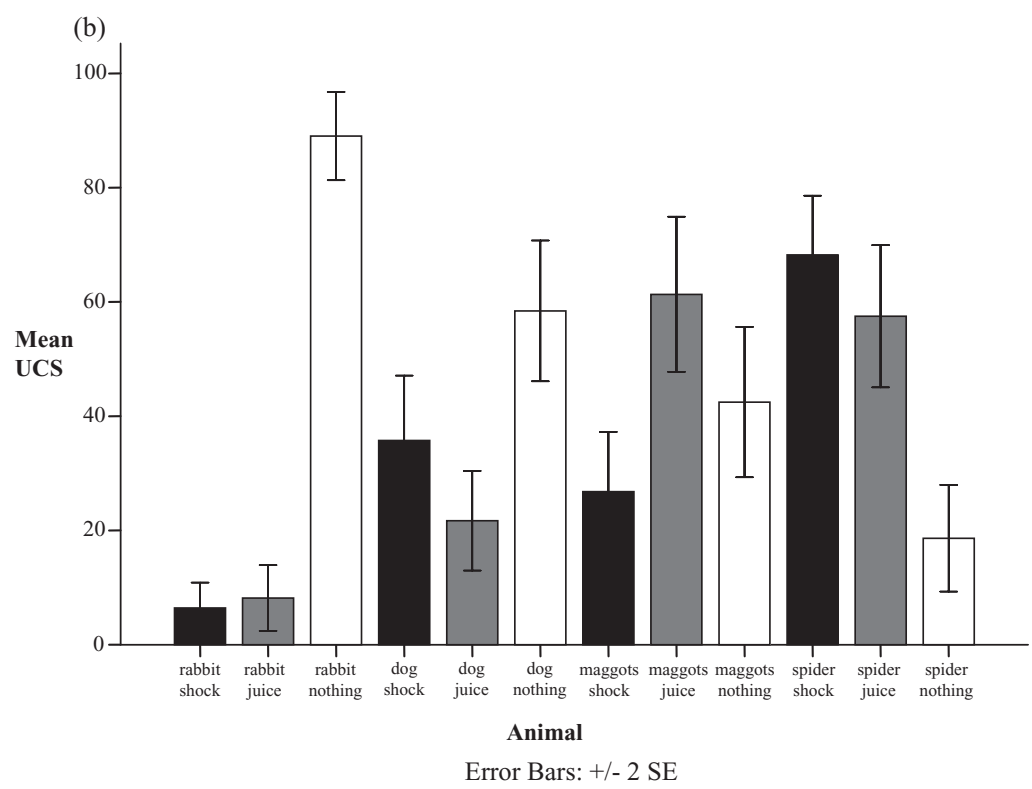

Figure 1. UCS expectancies for all Animals in (a) low spider fearful individuals $(n=30)$ and (b) high spider fearful individuals at pre-treatment measurement $(n=30)$

\section{DISCUSSION}

The main findings of the present study are: (1) high spider fearful participants displayed inflated spideroutcome expectancies for both contamination-related and harm-related outcomes and (2) following treatment both types of UCS-expectancies were reduced to normative levels.
In accordance with earlier findings (Davey et al., 2003; van Overveld et al., 2006, in press), participants generally expected either harm-related outcomes (shock) or nothing following exposure to a predation-related animal (growling dog), contamination-related outcomes (sip of nauseating, disgusting juice) following exposure to a 'dirty' contamination and disease-related animal (maggots) 
and no aversive outcome following exposure to a neutral animal (rabbit). This pattern of selective associations for these prototypical animal types was very similar for high and low spider fearful individuals. Although a higher-order interaction term was not observed, a priori hypothesis based testing showed that consistent with prior research (Cavanagh \& Davey, 2000; Diamond, Matchett, \& Davey, 1995; Kennedy, Rapee, \& Mazurski, 1997), the spider fearful group reported inflated UCS-expectancies for aversive outcomes to follow spiders. Adding to the idea that contaminationrelated preoccupations are somehow involved in spider fear, this UCS-expectancy bias was not restricted to harm-related outcomes but also evident for contamination-related outcomes (see van Overveld et al., 2006, de Jong \& Peters, 2007 for similar findings in undergraduate samples).

Most important for the present context, the UCSexpectancy biases for both types of aversive outcomes (shock and juice) were significantly lower in treated participants than in high spider fearful participants who did not yet receive treatment. Further, UCS-expectancy biases for aversive outcomes following presentation of a spider were effectively reduced to normative levels via treatment. This is in line with earlier studies that have shown that cognitive biases can be successfully modified as a result of treatment (e.g., de Jong et al., 1992) and consistent with the alleged reciprocal relationship between UCS expectancy bias and spider phobia (c.f. Mineka \& Sutton, 1992). No evidence emerged to suggest that harm and contamination-related UCS expectancies were differentially affected by treatment. Thus, the present findings provide no evidence to suggest that either harm or contamination-related outcome expectancies are more important in the maintenance of spider fear.

Several critical comments are in order. First, the present study relied on UCS-expectancies regarding hypothetical exposure to animals rather than actual exposure. UCS-expectancies in real-life situations may not fully correspond with those in hypothetical situations (e.g., Parkinson \& Manstead, 1993), it can therefore not be ruled out that the present results provide an inaccurate reflection of spider phobics' actual expectancies when being confronted with real spiders. However, because spider phobic individuals are normally quite successful in avoiding real-life phobic cues (and can rarely recall UCS experiences in connection to spiders; Davey, 1992b), it seems of major concern what type of UCS-expectancies people hold when they explicitly consider the possibility of exposure to a spider (c.f. de Jong, Merckelbach, Bögels, \& Kindt, 1998). It seems that such explicit considerations regarding the anticipated effects of exposure to a phobic object can be reasonably successfully investigated with a hypothetical thought experiment procedure.

Second, although the present pattern of findings is consistent with the alleged role of UCS expectancies in the maintenance of symptoms, it cannot be ruled out on the basis of this study that enhanced expectancy bias is a mere by-product of spider phobia. To more directly examine the important issue of causal contributions of UCS-expectancy biases, it would be critical to experimentally induce harm- and/or contamination-related UCSexpectancy biases in non-anxious individuals and to test whether such a manipulation would indeed result in heightened fear responses during exposure to spiders (see for such an approach in the context of attentional bias: Mathews \& Mackintosh, 2000; Mathews \& MacLeod, 2002). It should be noted, however, that this type of study might raise ethical concerns: if indeed UCS-expectancy biases play a causal role in the development of anxiety disorders, one should be very careful with such manipulations (remembering Watson's little Albert). An alternative approach, and even more exciting from a clinical stance, would be to examine whether the unlearning of UCS-expectancy biases in fearful individuals will be paralleled by a decrease of phobic complaints (c.f. Pauli, Montoya, \& Martz, 2001).

To conclude, consistent with previous research the present study indicates that both harm and contamination-related preoccupations are involved in spider fear. The finding that both types of UCS expectancies were similarly reduced following treatment is in line with the alleged reciprocal relationship between these cognitive biases and phobic fear. An important next step would be to experimentally reduce the UCS expectancy biases to test whether such procedure will also reduce phobic fear and avoidance.

\section{ACKNOWLEDGEMENTS}

For their efforts in the process of data collection, the authors express their gratitude to Agnes Garst, Margret Masselink, Fleur Smeding, Maartje Snieders and Maartje de Vries. Additionally, this research has been conducted as part of a larger project in Groningen. 


\section{REFERENCES}

Arntz, A., Lavy, E., van den Berg, G., \& van Rijsoort, S. (1993). Negative beliefs of spider phobics: A psychometric evaluation of the spider phobia beliefs questionnaire. Advances in Behavior Research and Therapy, 15, 257-277.

Cavanagh, K., \& Davey, G.C.L. (2000). UCS expectancy biases in spider phobics: Underestimation of aversive consequences following fear-irrelevant stimuli. Behaviour Research and Therapy, 38, 641-651.

Choy, Y., Fyer, J.D., \& Lipsitz, J.D. (2007). Treatment of specific phobias in adults. Clinical Psychology Review, 27, 266-286.

Davey, G.C.L. (1992a). An expectancy model of laboratory preparedness effects. Journal of Experimental Psychology, 121, 24-40.

Davey, G.C.L. (1992b). Characteristics of individuals with fear of spiders. Anxiety Research, 4, 299-314.

Davey, G.C.L. (1997). Phobias; a handbook of theory, research, and treatment. Chichester: Wiley.

Davey, G.C.L., Cavanagh, K., \& Lamb, A. (2003). Differential aversive outcome expectancies for high- and low-predation fear-relevant animals. Journal of Behavior Therapy and Experimental Psychiatry, 34, 117-128.

de Jong, P.J., \& Keijsers, G.P.J. (1999). Protocollaire behandeling van patiënten met een specifieke fobie: 1-sessie exposure in vivo. In G.P.J. Keijsers, A. van Minnen, \& C.A.L. Hoogduin (Eds.). Protocollaire behandelingen in de ambulante GGZ: Deel 2 (pp. 69-99). Zeist: Bohn Stafleu Van Loghum.

de Jong, P.J., Merckelbach, H., Arntz, A., \& Nijman, H. (1992). Covariation detection in treated and untreated spider phobics. Journal of Abnormal Psychology, 101, 724-727.

de Jong, P.J., Merckelbach, H., Bögels, S., \& Kindt, M. (1998). Illusory correlation and social anxiety. Behaviour Research and Therapy, 36, 1063-1073.

de Jong, P.J., \& Muris, P. (2002). Spider phobia: Interaction of disgust and perceived likelihood of involuntary physical contact. Journal of Anxiety Disorders, 16, 51-65.

de Jong, P.J., \& Peters, M.L. (2007). Contamination vs. harm-relevant outcome expectancies and covariation bias in spider phobia. Behaviour Research and Therapy, 45, 1271-1284.

de Jong, P.J., Vorage, I., \& van den Hout, M.A. (2000). Counterconditioning in the treatment of spider phobia: Effects on disgust, fear, and valence. Behaviour Research and Therapy, 38, 1055-1069.

Diamond, D., Matchett, G., \& Davey, G.C.L. (1995). The effect of prior fear levels on UCS-expectancy ratings to a fear-relevant stimulus. The Quarterly Journal of Experimental Psychology, 48, 237-247.

Huijding, J., \& de Jong, P.J. (2007). Beyond fear and disgust: The role of specific harm and contamina- tion-related associations in spider phobia. Journal of Behavior Therapy and Experimental Psychiatry, 38, 200211.

Jones, M.K., \& Menzies, R.G. (2000). Danger expectancies, self-efficacy and insight in spider phobia. Behaviour Research and Therapy, 38, 585-600.

Kennedy, S.J., Rapee, R.M., \& Mazurski, E.J. (1997). Covariation bias for phylogenetic versus ontogenetic fear-relevant stimuli. Behaviour Research and Therapy, 35, 415-422.

Klorman, R., Weerts, T.C., Hastings, J.E., Melamed, B.G., \& Lang, P.J. (1974). Psychometric descriptions of some specific fear questionnaires. Behavior Therapy, 5, 401-422.

Mathews, A., \& Mackintosh, B. (2000). Induced emotional interpretation bias and anxiety. Journal of Abnormal Psychology, 109, 602-615.

Mathews, A., \& MacLeod, C. (2002). Induced processing biases have causal effects on anxiety. Cognition and Emotion, 16, 331-354.

McNally, R.J., \& Heatherton, T.F. (1993). Are covariation biases attributable to a priori expectancy biases? Behaviour Research and Therapy, 31, 653-658.

Mineka, S., \& Sutton, S. K. (1992). Cognitive biases and the emotional disorders. Psychological Science, 3, 6569.

Öst, L-G. (1989). One-session treatment for specific phobias. Behaviour Research and Therapy, 27, 1-7.

Parkinson, B., \& Manstead, A.S.R. (1993). Making sense of emotion in stories and social life. Cognition and Emotion, 7, 295-323.

Pauli, P., Montoya, P., \& Martz, G.-E. (2001). On-line and a posteriori covariation estimates in panic-prone individuals: Effects of a high contingency of shocks following fear-irrelevant stimuli. Cognitive Therapy and Research, 25, 23-26.

Teachman, B.A., \& Woody, S.R. (2003). Automatic processing in spider phobia: Implicit fear associations over the course of treatment. Journal of Abnormal Psychology, 112, 100-109.

Tomarken, A.J., Mineka, S., \& Cook, M. (1989). Fearrelevant selective associations and covariation bias. Journal of Abnormal Psychology, 98, 381-394.

van Overveld, M., de Jong, P.J., \& Peters, M.L. (2006). Differential UCS expectancy bias in spider fearful individuals: Evidence toward an association between spiders and disgust-relevant outcomes. Journal of Behavior Therapy and Experimental Psychiatry, 37, 60-72.

van Overveld, M., de Jong, P.J., \& Peters, M.L. (in press). Disgust and fear-related UCS-expectancy bias in blood fearful individuals. Clinical Psychology and Psychotherapy.

Whittal, M.L., \& Goetsch, V.L. (1997). The impact of panic expectancy and social demand on agoraphobic avoidance. Behaviour Research and Therapy, 35, 813821. 


\section{APPENDIX}

\section{Thought Experiment}

This brief questionnaire studies how people perceive experimental research. This will be done by studying beliefs about certain animals.

\section{Description of the Experiment}

You are about to participate in a thought experiment. This means that we will ask you to imagine as vividly as possible the following situation. You are invited here to participate in an experimental study at the laboratory. You will be asked to sit down in a comfortable chair, and view a series of slides, projected on the large screen in the lab. Two electrodes will be placed on your upper arm and before the experiment starts a level of electrical shock will be selected in consultation with you. This will be done so the level is certainly unpleasant, yet not painful. During the experiment you will receive shocks at certain moments. Also, a catheter will be inserted in your mouth, and taped to your cheek, so at certain moments a fluid can be injected. This fluid will taste very bitter, and is quite nauseating. The fluid is, however, just like the shock, unpleasant yet harmless and without side effects.

During the experiments you will be shown a series of slides of four types of animals: dog, spiders, maggots and rabbits (at this point, some exemplary slides were shown of a growling dog, a spider, maggots and a white rabbit). Each slide will be shown for exactly six seconds and will immediately be followed by one of these three consequences: either you will receive a short but unpleasant electrical shock, or a shot of the nauseating, bitter fluid will be injected into your mouth, or nothing will happen.

Now imagine you are seated in the chair, with the electrodes attached to your right upper arm and the catheter inserted in your mouth. The light is waning and the first slide will soon appear on the screen. You may now fill in the questionnaire. 